CBESS Discussion Paper 13-11R

\section{Group Size and Matching Protocol in Contests by Kyung Hwan Baik* Subhasish M. Chowdhury ${ }^{\star *}$ Abhijit Ramalingam ${ }^{\star \star \star}$}

*Department of Economics, Sungkyunkwan University ${ }^{* *}$ CBESS and School of Economics, University of East Anglia

${ }^{* * *}$ CBESS and School of Economics, University of East Anglia

\begin{abstract}
We investigate the effects of partner and random stranger matching protocols in Tullock contests between two and between three players. In the groups of three players, we find no difference in the level or the dispersion of bids between matching protocols. For the two-player case, however, a partner matching results both in a lower level and a lower dispersion of bids - indicating tacit collusion. We conclude that unless one is interested in two-player contests or unless a particular matching protocol is required for the specific research, using a partner matching is preferred since it allows more flexibility in budget, logistics and data analysis. Furthermore, adding to the literature on group size, we find no difference in absolute bid levels due to group size across matching protocols. But the overbidding rate, defined as the bid over the Nash equilibrium level scaled with the Nash bid, is lower for the two-player groups.
\end{abstract}

\section{JEL classification codes}

B41, C72, C91.

\section{Keywords}

Contest, Experiment, Matching protocol, Group size, Experimental methodology.

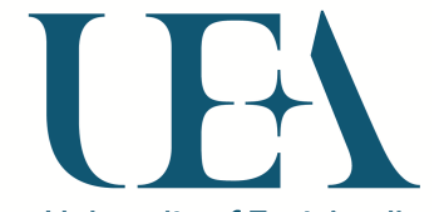

University of East Anglia

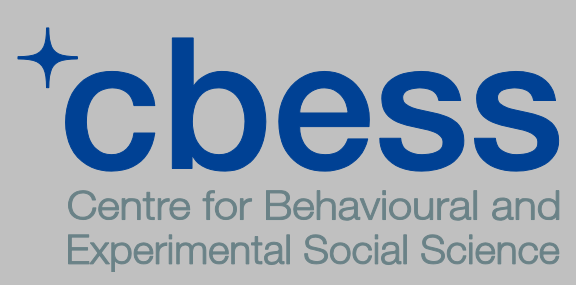

Centre for Behavioural and Experimental Social Science University of East Anglia Norwich Research Park Norwich NR4 7TJ United Kingdom www.uea.ac.uk/cbess 


\title{
Group Size and Matching Protocol in Contests
}

\author{
Kyung Hwan Baik, ${ }^{a}$ Subhasish M. Chowdhury, ${ }^{\mathrm{b}}$ Abhijit Ramalingam ${ }^{\mathrm{c}}$ \\ a Department of Economics, Sungkyunkwan University, Seoul 110-745, South Korea. \\ ${ }^{\mathrm{b}}$ School of Economics, Centre for Behavioural and Experimental Social Science, and Centre for \\ Competition Policy, University of East Anglia, Norwich NR4 7TJ, UK. \\ ${ }^{\mathrm{c}}$ School of Economics, and Centre for Behavioural and Experimental Social Science, University \\ of East Anglia, Norwich NR4 7TJ, UK.
}

This version: May 26, 2015

\begin{abstract}
We investigate the effects of partner and random stranger matching protocols in Tullock contests between two and between three players. In the groups of three players, we find no difference in the level or the dispersion of bids between matching protocols. For the two-player case, however, a partner matching results both in a lower level and a lower dispersion of bids - indicating tacit collusion. We conclude that unless one is interested in two-player contests or unless a particular matching protocol is required for the specific research, using a partner matching is preferred since it allows more flexibility in budget, logistics and data analysis. Furthermore, adding to the literature on group size, we find no difference in absolute bid levels due to group size across matching protocols. But the overbidding rate, defined as the bid over the Nash equilibrium level scaled with the Nash bid, is lower for the two-player groups.
\end{abstract}

JEL Classification: B41; C72; C91

Keywords: Contest; Experiment; Matching protocol; Group size; Experimental methodology

* Corresponding author: Subhasish M. Chowdhury (s.modak-chowdhury@uea.ac.uk)

An earlier version of this study was circulated as 'Matching Protocol in Contest Experiments'. We thank Paolo Crosetto, Werner Güth, Volodymyr Lugovskyy, Roman Sheremeta, Bob Sugden, Ted Turocy, Daniel Zizzo, the seminar participants at the University of East Anglia, and the participants at the ESI Autumn Workshop at the MPI Jena for useful comments, and Melanie Parravano and Ailko van der Veen for research assistance. We retain responsibility for any remaining errors. 


\section{Introduction}

Contests are situations in which people expend costly and irreversible resources in order to win prizes. Tullock (1980) coined a specific type of contest in which contestants make sunk bids, and the probability of winning is the ratio of one's bid to the total bids made by all the contestants. Various real life situations such as patent races, rent-seeking games, lotteries, promotional tournaments, sports, litigation, warfare and terrorism can be modeled as such a contest. In many of these cases, players take part in the contest repeatedly and there are important aspects - usually out of the control of the players - that affect their behavior. Two such prominent aspects are how those players are matched in the repetitions (known as the 'matching protocol'), and the number of contesting players (often called the 'group size'). In some contests, e.g., protracted war with repeated battles, the same set of players compete for prizes repeatedly. In others, such as in lotteries, they largely compete with different players each time. Furthermore, in some contests, as in sports, only a handful of players compete for the prize at a time; while in others, again as in lotteries, many players compete for the same prize.

It is well known that repeated interactions can have important reputation effects and can thus influence behavior. In repeated contests among the same set of players, players may draw inferences about others' types, in terms of willingness to tacitly collude, spitefulness etc., and signal their own type. Such behavior can be particularly strong in small groups in which observing and processing the actions of others are relatively easy. Consequently, in addition to independent effects, matching protocol and group size can have significant intertwined effects on behavior in contests. Gaining a deeper understanding of this issue is thus important. Standard theory provides specific predictions on the effects of group size, but is silent on the effects of matching protocol. Field data on contests are hard to obtain, and when available, are often noisy. But laboratory or field experiments allow control and clear identification of causal channels, providing a reliable way to analyze these issues. However, as we elaborate in the next section, no existing experimental study of contests investigates the issue of matching protocol - let alone its intertwined effects with group size. In this study we employ a laboratory experiment designed to investigate the effects of matching protocol, group size, and their interplay, on behavior in finitely repeated Tullock contests. Our results provide a two-fold contribution. First, it allows a better understanding of the underpinning mechanisms of behavior in contests. Second, at a methodological level our study provides direction to other contest experiments that rely on a repeated setting. 
A repeated contest among the same players is operationalized in the lab using a partner matching protocol, in which subjects in the same subset of a cohort interact with each other throughout an experimental session. This is in contrast to a stranger matching in which groups of subjects are re-matched in every period of a session. ${ }^{1}$ It is observed in various experiments that a partner matching often results in reputational effects and collusion. ${ }^{2}$ Since contest experiments are known to record overbidding of resources relative to the equilibrium (Dechenaux et al., 2014), a partner matching may allow players in contests as well to tacitly collude and reduce wasteful overbidding. It is also shown in the experimental literature that collusion is easier among a limited number of players (Huck et al., 2004). One would thus expect the effects of matching protocol to interact with the number of players in a contest as well.

In this study we begin with group size 3, which is commonly used in the contest experiments (Dechenaux et al., 2014) and in the market experiments on cartels (Huck et al., 2004). We then employ group size 2 , the size that has been found to be most likely to elicit tacit collusion in other settings. Consistent with existing studies, we find significant overbidding in all treatments. There is no difference in bids or in the overbidding rates between the two matching protocols for group size 3. However, both bids and overbidding rates are significantly lower with partner matching than in stranger matching for group size 2 . We find that a lower group size does not lead to an increase in bids. As a result the overbidding rate is reduced in smaller groups across matching protocols. Our results imply that while smaller groups are able to reduce overbidding under both matching protocols, it is more prominent under partner matching.

These results are of importance for several reasons. First, they allow one to identify the effects matching protocol and group size have on a contest, and thus provide a better understanding of contest design. Second, the results suggest that unless one is interested in 2-player contests, the matching protocol does not significantly alter behavior. However, in terms of logistics, a partner matching might be preferable. This is because in the partner treatments, each group forms an

\footnotetext{
${ }^{1}$ There are mainly two types of stranger matching employed in the experimental literature. In a 'perfect stranger' matching a subject is matched with another subject only once in a whole session. In a 'random stranger' matching the subjects are randomly re-matched in each period and two subjects may be matched more than once (Botelho et al., 2009). In this study, we focus on the random stranger protocol as this is "by far the most popular operational counterpart of a one-shot environment in experiments" (Botelho et al., 2009, p. 254), including contests. We use the terms 'stranger' and 'random stranger' interchangeably in this study.

${ }^{2}$ For e.g., Andreoni and Miller (1993) in Prisoners' dilemma and Croson (1996) and Fehr and Gächter (2000) in public goods games find higher level of cooperation among subjects when a partner matching is employed, and especially when players can use disciplining mechanisms viz. punishment (Fehr and Gächter, 2000). This is argued to be due to reputation and reciprocity effects, which a stranger matching eliminates (Andreoni and Croson, 2008). See also Chowdhury and Crede (2015) and the references therein for similar results in market experiments.
} 
independent observation since there is no spillover across groups even within a session. However, in the stranger treatments subjects participate in different groups in each period and each session represents an independent observation in the stranger treatments. Hence, for the same budget a stranger matching protocol provides a smaller number of independent observations. Furthermore, the possibility of contamination of the whole session by technical glitches or due to extreme behavior by even one subject poses a larger risk under stranger matching than in partner matching where data contamination is limited to one group. The third result, hence, makes the argument for employing a partner matching even stronger. Finally, as we discuss in the next section, the effect of group size is not undisputed in the literature. This study permits this area of literature to have a clearer understanding while considering matching protocol.

The rest of the paper is organized as follows. We cover the relevant areas of literature in the next section. In Section 3 we provide a theoretical benchmark for the experiment and Section 4 elaborates our experimental procedures. Section 5 presents our hypotheses and Section 6 reports the results. Section 7 concludes.

\section{Literature Review}

There exists a small body of work that looks at matching protocol in a variety of contests. Mentioning the issue for the first time, Durham et al. (1998) observe traces of collusion, in the sense of lower bidding, in a production and conflict game when a partner matching is employed. However, the effects of matching protocol are not tested here. Lugovskyy et al. (2010) find that bids in an all-pay auction are lower with a partner matching than with a stranger matching, but not statistically significantly so. Lacomba et al. (2011) observe lower post-conflict bids under partner matching in a production-conflict framework, but the significance of the result is not tested. Chowdhury et al. (2013) investigate the Colonel Blotto game, a multi-battle contest, and observe serial correlation in bids across periods in a given battlefield. They find that such correlation is significantly reduced under partner matching. Vandegrift and Yavas (2010) study a tournament with the option to sabotage the opponent. Both the levels of bids and sabotage decrease when a partner matching is employed. Finally, investigating the level of bids in his meta-analysis, Sheremeta (2013) uses an indicator variable for matching protocol. The coefficient turns out to be insignificant.

Hence, existing studies analyzing the effects of matching protocol are either concentrated on mechanisms different from standard contests, or on research questions in which other issues 
such as production or sabotage are conjoined along with bids. Oftentimes the descriptive statistics show mixed results and statistical tests are not run. Experimental studies of Tullock contests typically use either a partner or a random stranger matching protocol. In his meta-analysis, for example, Sheremeta (2013) considers 28 well known experimental studies in spanning the years 1989 to 2013. Of these, 9 studies use partner matching, 16 use random stranger matching, and the remaining 3 are one-shot experiments. There exists no study testing the effects of matching in this environment and thus "there is no agreement on how matching protocol influences individual behavior" (Sheremeta, 2013, p. 508).

Turning to group size effects, existing work on collusion among firms in a market suggests an increase in collusion (i.e., reduced competition) with a decrease in group size. Selten (1973) shows theoretically that collusion becomes more difficult as the number of firms in the market increases. Dolbear et al. (1968) show that collusion becomes more successful when the number of firms in the experimental market is decreased linearly from four to two. Dufwenberg and Gneezy (2000) find collusion among two price-setting firms but also find that collusion breaks down with 3 or 4 firms in the market. In a Cournot setting, Huck et al. (2004) reaffirm that collusion works well in markets with two firms but its effectiveness declines in larger markets. Fonseca and Normann (2012) find such a negative relationship also in a Bertrand setting.

Theory in symmetric Tullock contests predicts a decrease in competition, i.e., individual bids, with an increase in group size. Experimental evidence on group size effects in contests, however, is mixed. In a context including cost heterogeneity and contest entry fees, Anderson and Stafford (2003) study behavior in homogeneous groups with 2, 3, 4, 5 or 10 players and find support for the theoretical prediction. Sheremeta (2011) indirectly observes an effect of group size on bids; he observes lower bids in a grand contest with four players than in two sub-contests with two players each. Morgan et al. (2012) find support for a negative relation between bids and group size in contests with entry and endogenous group size. To our knowledge, Lim et al. (2014) is the only study specifically designed to investigate bidding in Tullock contests with exogenously varying group sizes. They find, under a stranger matching protocol, that group size does not significantly affect individual bids and explain the phenomenon with bounded rationality models.

Thus, the effects of group size on bids in Tullock contests have not been investigated by most of the literature. The only study specifically investigating this issue (Lim et al., 2014) does not find support for the predictions of contest and collusion literature, and do not explore the effects of matching protocol. In this study we design an experiment to fill in this gap. 


\section{Theoretical Background}

We consider a rent-seeking contest with $N$ identical risk-neutral players each with budget $B$. Player $i$, for $i=1,2,3, \ldots N$, chooses his bid $b_{i} \in[0, B]$ to win a single prize of common value $V>0$. Irrespective of the outcome of the contest, players forgo their bids. The probability that player $i$ wins the prize, $p_{i}\left(b_{i}, \boldsymbol{b}_{-\boldsymbol{i}}\right)$, where $\boldsymbol{b}_{-\boldsymbol{i}}$ is the vector of bids of all players except $i$, is represented by a lottery contest success function (Tullock, 1980):

$$
p_{i}\left(b_{i}, \boldsymbol{b}_{-i}\right)=\left\{\begin{array}{cl}
b_{i} / \sum_{j} b_{j} & \text { if } \sum_{j} b_{j} \neq 0 \\
1 / N & \text { otherwise }
\end{array}\right.
$$

Given (1), the expected payoff for player $i, E\left(\pi_{i}\right)$, can be written as

$$
E\left(\pi_{i}\right)=p_{i} V+\left(B-b_{i}\right)
$$

Following standard procedures, the Nash equilibrium bid is: ${ }^{3}$

$$
b^{*}=(N-1) V / N^{2}
$$

And the expected payoff at the Nash Equilibrium is:

$$
\pi^{*}=B+V / N^{2}
$$

The equilibrium remains the same in a finitely repeated contest with either the same or different rivals in each repetition. Note that this theoretical model provides us with two precise predictions. First, the equilibrium bid decreases with an increase in group size. Second, the equilibrium bid is unaffected by the matching protocol.

\section{Experimental Design and Procedure}

In all sessions, subjects played the contest game described above repeatedly for 25 periods. In each period a group of $N$ players competed for a prize of 180 tokens, i.e., $V=180$. Each player was given a budget of $B=180$ tokens in each period which they could use to bid for the prize. Players could enter bids up to one decimal place. At the end of each period, subjects received feedback on the total of all bids in their group and whether or not they won the prize. While they competed in each of the 25 periods, subjects were paid their average earnings in five of these periods chosen randomly. All design elements were made public knowledge to all subjects in every session.

\footnotetext{
${ }^{3}$ We ensure in the experiment that the budget is larger than the equilibrium bid i.e., $B>(N-1) V / N^{2}$.
} 
We employed a $2 \times 2$ factorial design varying two dimensions - matching protocol (partner vs. random stranger) and group size (2 vs. 3), resulting in four treatments. In each session of the Partner treatment the $N$ subjects were matched as one set of contestants, and the matching did not change during the session. However, the matching changed randomly in every period of the Random Stranger treatment. These were made clear in the instructions (included in the Appendix).

Equation (2) provides us with the equilibrium bid in each of the 25 periods. The equilibrium bid is 40 tokens for group size 3 and 45 tokens for group size 2. Table 1 summarizes the design and presents the number of subjects in each treatment. We denote the treatment with partner matching and group size 3 as Partner 3 and so on.

Table 1. Summary of treatments (number of subjects)

\begin{tabular}{lcc}
\hline & \multicolumn{2}{c}{ Group size } \\
\hline Matching protocol & $N=3$ & $N=2$ \\
\hline Partner & Partner 3 (54) & Partner 2 (36) \\
Stranger & Stranger 3 (54) & Stranger 2 (36) \\
\hline Equilibrium bid & 40 & 45 \\
\hline
\end{tabular}

The parameters have been chosen with sufficient care. ${ }^{4}$ We chose a group size of three to ensure that a 'baseline' resembles the standard contest experiment designs. Group size 2 provides one with a best-shot at signals over repeated interaction and possible tacit collusion when a partner matching is implemented (Fonseca and Normann, 2012). The number of subjects is higher in the group size 3 treatments to keep the number of competing groups, 18, the same across treatments.

The prize value was chosen such that the equilibrium bid is a round number in both group sizes and thus provides a straightforward theoretical comparison of equilibrium bids across the two. It could have been possible to simultaneously change the group size as well as the prize value to keep the Nash equilibrium bid the same, and investigate any difference in observed bids. We instead chose to follow the standard procedure and changed only one element at a time.

The computerized experiment was run at a laboratory of the Centre for Behavioural and Experimental Social Science at the University of East Anglia using z-tree (Fischbacher, 2007). The subjects were students from the University and the 18 subjects in each of the 10 sessions were

\footnotetext{
${ }^{4}$ We thank Roman Sheremeta for very useful discussions regarding the design.
} 
recruited through ORSEE (Greiner, 2004). Each session had two parts. First, we ran the Eckel and Grossman (2008) version of the risk elicitation task introduced by Binswanger (1981), but the outcome of the task was not revealed until the end of the experiment. The second part consisted of the 25 periods of the contest. At the end of each session we collected demographic information through a survey. No subject had participated in any contest experiment before, but they might have participated in other economics experiments. Each session lasted for around 50 minutes. At the end of each session, token earnings were converted to GBP at the rate of 1 token to 3 pence. Subjects, on average, earned $£ 7.82$.

\section{Hypotheses}

The action space for players in all the treatments is the same: $[0,180]$. We can thus easily compare the absolute levels of bids across treatments in a straightforward manner. A robust finding in the experimental literature on contests is that subjects consistently overbid, i.e., bid more than the theoretically predicted Nash equilibrium bid level (Dechenaux et al., 2014). We do not expect a different result and state it formally as our first hypothesis.

Hypothesis 1. There exists overbidding across group sizes and across matching protocols.

For finitely repeated contests, theory predicts the same level of bids in equilibrium when the group size is the same - irrespective of the matching protocol. This is hypothesis 2.

Hypothesis 2. There exists no difference in individual bid levels across matching protocols for a fixed group size.

Although we expect overbidding across treatments, theory clearly predicts a higher equilibrium bid for a lower group size. This is reflected in the next hypothesis.

Hypothesis 3. Individual bids are higher in the treatments with group size 2 than in the treatments with group size 3 under both matching protocols.

\section{Results}

\subsection{Bidding behavior}

We first present summary statistics of individual bids in each treatment, averaged over all 25 periods. Table 2 presents means and standard deviations for each treatment cell. 
Table 2. Means (standard deviations) of individual bids

\begin{tabular}{lcc}
\hline & \multicolumn{2}{c}{ Group size } \\
\hline $\begin{array}{l}\text { Matching } \\
\text { protocol }\end{array}$ & $\mathrm{N}=3$ & $\mathrm{~N}=2$ \\
\hline Partner & 61.184 & 53.926 \\
& $(33.083)$ & $(23.335)$ \\
Stranger & 63.146 & 58.872 \\
& $(28.675)$ & $(21.983)$ \\
\hline Obs. (per cell) & 54 & 36 \\
\hline Equilibrium bid & 40 & 45 \\
\hline
\end{tabular}

It can be observed from Table 2 that average bids are above the equilibrium predictions in all treatments. Also, both the level and dispersion of bids for group size 3 are higher than the ones for group size 2. Finally, average bids in the stranger treatment are higher than those in the partner treatment in both group sizes.

To gain a further understanding, in Figure 1 we plot the average bids over periods (left panel) and over the bid range (right panel). The left panel confirms that overbidding occurs throughout the periods in all treatments. The right panel also shows that in the treatments with group size 3, bids are distributed over the whole bid range while bids are concentrated below 120 in the treatments with group size 2. Furthermore, as observed in Table 2, dispersion in bids is higher in the Partner treatments for both group sizes. We first focus on the level of bids, and discuss the dispersion of bids in Section 6.3.

Figure 1. Average bids over periods and over the bid-range
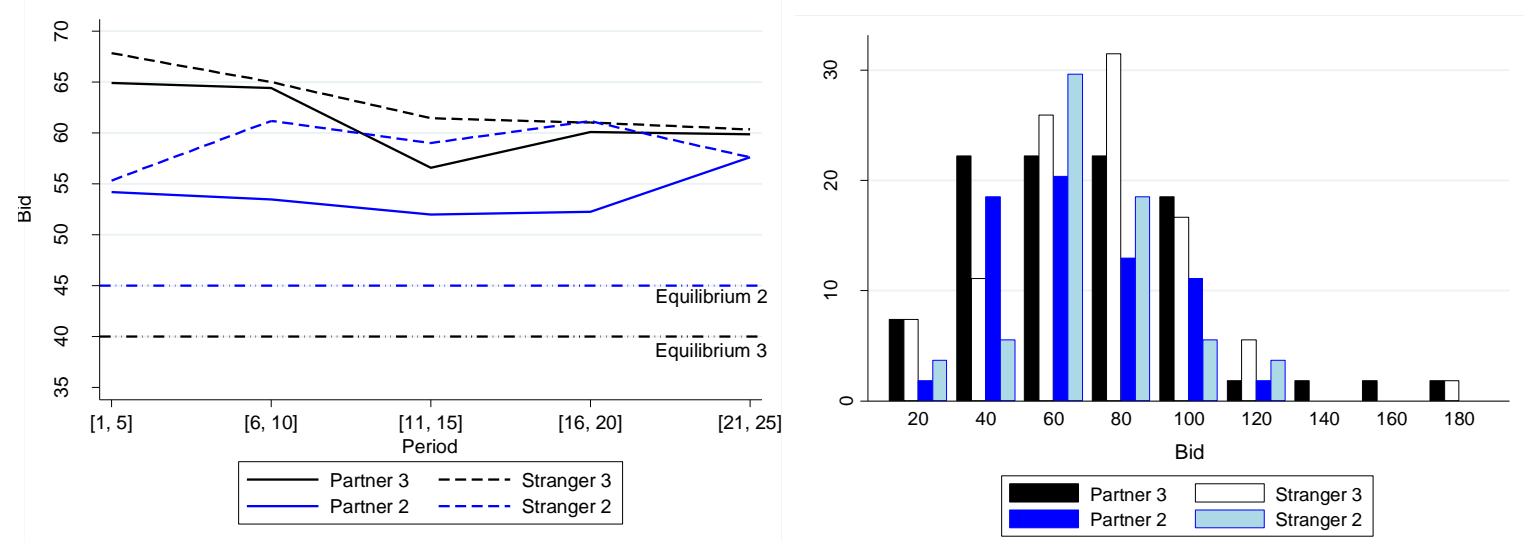
These observations are in line with the existing results on overbidding and overspreading in contests (Chowdhury et al., 2014; Lim et al., 2014), and show that they are robust to the choice of matching protocol and group size. We now test the statistical significance of these observations. We estimate four individual-level panel random effects regressions, for each treatment, on a constant and a dummy (stranger treatment when we consider group size, and group size 2 when we consider matching protocol). The dependent variable is the deviation of an individual's bid from the equilibrium bid $\left(=b_{i}-b^{*}\right)$ in a period. Since we are only interested in means relative to the equilibrium, we do not control for other individual characteristics at this stage. To account for the lack of independence within sessions in the stranger treatments, we calculate standard errors clustered at the session level. A significant positive coefficient of the constant term would constitute evidence of significant overbidding. The results are presented in Table 3.

Table 3. Overbidding: panel random effects regressions

\begin{tabular}{|c|c|c|c|c|}
\hline \multirow{2}{*}{ Dep var: $\left(b_{i}-b^{*}\right)$} & \multicolumn{2}{|c|}{ Group size } & \multicolumn{2}{|c|}{ Matching protocol } \\
\hline & $\mathrm{N}=3$ & $\mathrm{~N}=2$ & Partner & Stranger \\
\hline $\begin{array}{l}\text { Stranger matching } \\
\text { Indicator }\end{array}$ & $\begin{array}{c}1.962 \\
(5.589)\end{array}$ & $\begin{array}{l}4.946^{* * *} \\
(0.989)\end{array}$ & & \\
\hline $\begin{array}{l}\text { Group size } 2 \\
\text { Indicator }\end{array}$ & & & $\begin{array}{c}-12.258^{* * *} \\
(3.824)\end{array}$ & $\begin{array}{c}-9.274^{* *} \\
(4.342)\end{array}$ \\
\hline Constant & $\begin{array}{c}21.184^{* * * *} \\
(3.639)\end{array}$ & $\begin{array}{l}8.926^{* * *} \\
(0.935)\end{array}$ & $\begin{array}{c}21.184^{* * * *} \\
(3.715)\end{array}$ & $\begin{array}{c}23.146^{* * * *} \\
(4.331)\end{array}$ \\
\hline$R^{2}$ & 0.0004 & 0.01 & 0.02 & 0.01 \\
\hline Observations & 2700 & 1800 & 2250 & 2250 \\
\hline
\end{tabular}

Figures in parentheses are robust standard errors clustered on sessions. ${ }^{*} p<0.10,{ }^{* *} p<0.05,{ }^{* * *} p<0.01$.

The coefficient estimates of the constant are positive and significant at the $1 \%$ level in each of the regressions, implying overbidding in each of the treatments separately. This is summarized in Result 1 below.

Result 1. Observed bids are significantly higher than the equilibrium bids for both the group sizes and for both matching protocols. 
The first two regressions specify that the bids are significantly above equilibrium in the partner treatment across group sizes. The positive coefficients of the stranger dummies (which is significant only for group size 2) further show that the overbidding in the stranger treatment is at least as high as the overbidding in the partner treatment for group size 3 and strictly higher for group size 2 . The negative and significant coefficients of the group size 2 indicator in the next two regressions further confirm that the overbidding is lower for a smaller group than a bigger one across matching protocols. Result 2 summarizes these findings and, combined with Result 1, provides support for Hypothesis 1.

Result 2. Overbidding is more prominent for group size 3 across matching protocols. Further, when a stranger matching is employed, overbidding increases only for group size 2.

\subsection{Effects of matching protocol and group size}

We now analyze the effects of matching protocol and group size on bidding behavior, while controlling for other factors. We estimate individual-level random effects panel regressions where an individual's bid in a period is the dependent variable and include additional controls on observed past outcomes: one-period lagged value of own bid, an indicator for whether or not the individual won the contest in the previous period and the total bids of the others in the group in the previous period. ${ }^{5}$ We also control for an individual's demographic characteristics. In particular, we include a female gender dummy, participant age (in years), and an indicator for a preference for risky behavior. The risk elicitation task had six options (1-6) in increasing order of risk. The risky behavior indicator takes the value 1 for subjects who chose option 4-6 and 0 otherwise (the results are robust to alternative definitions of the indicator). In addition, we include a time trend (Period). To account for the lack of independence within sessions in the stranger treatments, we calculate standard errors clustered at the session level. The regression results are in Table 4.

Table 4. Bidding behavior: random effects panel regressions

\begin{tabular}{|c|c|c|c|c|}
\hline \multirow{2}{*}{ Dep Var: Bid } & \multicolumn{2}{|c|}{ Group size } & \multicolumn{2}{|c|}{ Matching protocol } \\
\hline & $\mathrm{N}=3$ & $\mathrm{~N}=2$ & Partner & Stranger \\
\hline $\begin{array}{l}\text { Stranger matching } \\
\text { Indicator }\end{array}$ & $\begin{array}{c}0.917 \\
(1.978)\end{array}$ & $\begin{array}{l}0.748^{* * *} \\
(0.276)\end{array}$ & & \\
\hline
\end{tabular}

${ }^{5}$ Note that for group size 2 this is simply the bid of the other person in the group in the previous period. 


\begin{tabular}{|c|c|c|c|c|}
\hline $\begin{array}{l}\text { Group size } 2 \\
\text { Indicator }\end{array}$ & & & $\begin{array}{l}-0.154 \\
(4.028)\end{array}$ & $\begin{array}{l}-0.481 \\
(2.050)\end{array}$ \\
\hline Lag of own bid & $\begin{array}{l}0.528^{* * *} \\
(0.046)\end{array}$ & $\begin{array}{l}0.600^{* * *} \\
(0.054)\end{array}$ & $\begin{array}{l}0.604^{* * *} \\
(0.043)\end{array}$ & $\begin{array}{c}0.505^{\text {*** }} \\
(0.062)\end{array}$ \\
\hline Previous period win indicator & $\begin{array}{c}0.763 \\
(0.856)\end{array}$ & $\begin{array}{c}-3.144^{* * *} \\
(0.535)\end{array}$ & $\begin{array}{c}-3.087^{* *} \\
(1.531)\end{array}$ & $\begin{array}{c}-0.155 \\
(1.281)\end{array}$ \\
\hline Lag of others' bid & $\begin{array}{c}0.004 \\
(0.023)\end{array}$ & $\begin{array}{l}0.163^{* * *} \\
(0.059)\end{array}$ & $\begin{array}{c}0.021 \\
(0.044)\end{array}$ & $\begin{array}{c}0.026^{\text {**** }} \\
(0.010)\end{array}$ \\
\hline Period & $\begin{array}{c}-0.286^{* * *} \\
(0.111)\end{array}$ & $\begin{array}{c}0.049^{*} \\
(0.025)\end{array}$ & $\begin{array}{l}-0.068 \\
(0.103)\end{array}$ & $\begin{array}{l}-0.202 \\
(0.142)\end{array}$ \\
\hline Risky behavior indicator & $\begin{array}{l}5.759^{*} \\
(3.253)\end{array}$ & $\begin{array}{c}-0.954 \\
(3.086)\end{array}$ & $\begin{array}{l}-0.466 \\
(2.033)\end{array}$ & $\begin{array}{c}7.836^{*} \\
(4.047)\end{array}$ \\
\hline Female indicator & $\begin{array}{c}1.897^{*} \\
(1.013)\end{array}$ & $\begin{array}{l}1.067^{* *} \\
(0.533)\end{array}$ & $\begin{array}{l}2.573^{* * *} \\
(0.570)\end{array}$ & $\begin{array}{c}2.299 \\
(1.406)\end{array}$ \\
\hline Age & $\begin{array}{l}-0.317 \\
(0.391)\end{array}$ & $\begin{array}{l}-0.053 \\
(0.292)\end{array}$ & $\begin{array}{l}-0.036 \\
(0.241)\end{array}$ & $\begin{array}{c}-0.663 \\
(0.626)\end{array}$ \\
\hline Constant & $\begin{array}{l}35.44^{* * *} \\
(11.53)\end{array}$ & $\begin{array}{l}15.23^{* *} \\
(6.809)\end{array}$ & $\begin{array}{l}22.95^{* *} \\
(10.16)\end{array}$ & $\begin{array}{l}40.41^{* *} \\
(17.08)\end{array}$ \\
\hline$R^{2}$ & 0.29 & 0.43 & 0.36 & 0.29 \\
\hline Observations & 2592 & 1728 & 2160 & 2160 \\
\hline
\end{tabular}

Figures in parentheses are robust standard errors clustered on sessions. ${ }^{*} p<0.10,{ }^{* *} p<0.05,{ }^{* * *} p<0.01$.

Let us first consider the effects of matching protocol. The coefficient of the stranger matching indicator is positive for both the group sizes and significant at $1 \%$ level for group size 2 but is not significant for group size 3. This indicates that the matching protocol does not have an effect on bidding behavior for group size 3. But for group size 2, which provides the best-shot for possible tacit collusion, a partner matching indeed reduces the bids. The controls in general show expected signs and significance levels. ${ }^{6}$ This is summarized in the Result 3.

\footnotetext{
${ }^{6}$ The results such as auto-correlated bids and higher bids by females are well known in the literature (Price and Sheremeta, 2012). Some other results such as strategic interaction variables e.g., lag of rival's bid, or own win is significant only for group size 2 reflects reputation effects. There is also an end period effect after 20 periods for group
} 
Result 3. Bids are not significantly different between matching protocols in group size 3. However, bids are significantly lower under partner matching than under stranger matching in group size 2.

Result 3 provides mixed support for Hypothesis 2 . When the group size is fixed at 3, the hypothesis cannot be rejected that the matching protocol does not affect bidding behavior. However, in line with the observation from experimental industrial organization, a partner matching with only two players invokes possible tacit collusion, and as a result significantly lower bids, thus rejecting the hypothesis.

Turning to the effects of group size we focus on the last two regressions. The coefficient of the group size 2 indicator is negative but not significant for both matching protocols. The effects of the controls are, again, standard. The result is formally stated below. This result allows us to reject Hypothesis 3 that the bid is higher for the smaller group size.

Result 4. For both matching protocols, bids are not significantly different across group sizes.

Our result is in line with Lim et al. (2014) who also find no effect of group size for many group sizes (albeit employing only a stranger matching protocol) and more spread in equilibrium bids. However, since the equilibrium bid is higher in the smaller groups, the same bid implies a lower rate of overbidding (relative to the equilibrium) in smaller groups. Thus a comparison of the absolute bids across treatments, while interesting, presents only a partial picture of the behavioral anomalies relative to the equilibrium prediction.

To compare overbidding behavior between the two group sizes, we define individual $i$ 's overbidding rate (Sheremeta, 2013), $r_{i}$, as follows:

$$
r_{i}=\left(b_{i}-b^{*}\right) / b^{*}
$$

Thus, $r_{i}=0$ if and only if the bid equals the equilibrium prediction. A negative (positive) value indicates underbidding (overbidding) relative to equilibrium.

Table 5 provides descriptive statistics for the overbidding rate (that is comparable to the information about bid levels in Table 2). It can be observed that overbidding rates (and its dispersions) are higher for group size 3 across matching protocols. Also, average overbidding rates in the partner treatment are lower than those in the stranger treatment in both group sizes.

size 2 (as can also be observed in Figure 1) possibly due to break-down of tacit collusion under partner matching making the effect of time trend weakly positive whereas for all the other cases the effect is negative. 


\section{Table 5. Means (standard deviations) of overbidding rates}

\begin{tabular}{lcc}
\hline & \multicolumn{2}{c}{ Group size } \\
\hline $\begin{array}{l}\text { Matching } \\
\text { protocol }\end{array}$ & $\mathrm{N}=3$ & $\mathrm{~N}=2$ \\
\hline Partner & 0.529 & 0.198 \\
& $(0.827)$ & $(0.519)$ \\
Stranger & 0.579 & 0.308 \\
& $(0.717)$ & $(0.489)$ \\
\hline Obs. (per cell) & 54 & 36 \\
\hline Equilibrium bid & 40 & 45 \\
\hline
\end{tabular}

We run random effects panel regressions as in Table 4 but now consider the overbidding rate as the dependent variable. The independent variables are the same as those in the regressions reported in Table 4. Similar to bids, the overbidding rate is also lower with a partner matching for group size 2 but is not different across matching protocols for group size 3. The effect of group size, however, is different from that observed on bidding behavior. Under both matching protocols, overbidding rates are significantly lower for the smaller group. The observed bids are not significantly different across group size, but the equilibrium bid for the smaller group size is higher. So, once we scale the observed bids with the equilibrium bids, the resulting overbidding rate for the smaller-group turns out to be smaller. These findings are summarized in Result 5 and regression results are reported in Appendix A.

Result 5. The overbidding rate is lower with a partner matching compared to a stranger matching only for group size 2. Across matching protocols the overbidding rate is lower for group size 2.

\subsection{Dispersion in bids}

As observed from Table 2 and Figure 1(left panel), there are differences in dispersion across treatments. In particular, the standard deviations of average individual bids are lower in smaller groups. We now test to see if these differences are significant.

Although understanding the bid dispersion behavior is important for various practical purposes, the existing contest literature does not usually focus on analyzing this issue. ${ }^{7}$ In this study we propose two measures of dispersion in individual bids: (I) the standard deviation of an

\footnotetext{
${ }^{7}$ An exception is Chowdhury et al. (2014) who analyze the phenomenon and term it as 'overspreading'.
} 
individual's bids over all 25 periods, and (II) the standard deviation of all individual's bids in each period. Measure I provides us with one observation per individual whereas measure II provides us with 25 observations for each session, one for each period of the contest.

Once again, we use regressions to tests for differences across treatments. We estimate two OLS regressions for measure I, one for each matching protocol, on a dummy for group size 2 and a constant. Using measure II, we estimate two panel random effects regressions, again one for each matching protocol, on a dummy for group size 2, a period time trend and a constant. In all regressions, we calculate standard errors clustered at the session level. Table 6 presents the coefficient estimates of the group size dummy in each of the four regressions.

Table 6. Dispersion in bids: regression estimates of the group size dummy

\begin{tabular}{lcc}
\hline Matching & Measure I & Measure II \\
\hline Partner & $-9.819^{*}$ & $-13.666^{* * *}$ \\
& $(3.722)$ & $(2.701)$ \\
Stranger & $-11.292^{* * *}$ & $-13.165^{* * *}$ \\
& $(1.222)$ & $(2.108)$ \\
& 90 & 125 \\
Obs. & OLS & Panel RE \\
\hline
\end{tabular}

Figures in parentheses are robust standard errors clustered on sessions. ${ }^{*} p<0.10,{ }^{* *} p<0.05,{ }^{* * *} p<0.01$.

Table 6 shows that the dispersion in bids, with both measures and across matching protocols, is indeed significantly lower in smaller groups. This is summarized below.

Result 6. Dispersion in bids is lower for group size 2 across matching protocols.

The regressions in Table 4 suggest an explanation for this finding. The regressions show that individuals do not respond to the (lagged) bids of others in group size 3. On the other hand, individuals in smaller groups do respond to the bids of others. In particular, the positive (and significant) coefficient of the lag of the others' bid suggests that bids move together, thus reducing variation in bids of individuals in small groups. ${ }^{8}$

\footnotetext{
${ }^{8}$ We estimate similar regressions to test if dispersion is higher under stranger matching than under partner matching in each group size and do not find any significant difference. For the sake of brevity we do not report these regression estimates. The results are available upon request.
} 


\section{Discussion}

In various real life situations individuals take part in a contest repeatedly. Two crucial factors that may affect an individual's behavior in such cases are whether he is matched with the same set of players in every repetition (matching protocol), and how many players are engaged in the contest (group size). Repeated interaction with the same set of players can have reputational issues and trigger one's attempt to collude tacitly. This may become even easier with a small number of players. Hence, the effects of matching protocol and group size in behavior in contests are important as well as intertwined. We investigate these effects in Tullock-type contests.

We employ a $2 \times 2$ experimental design to investigate the effects of two most commonly used matching protocols: partner and Random stranger, in two different group sizes: 2 and 3. We find that neither repeated play nor a small group size eliminates overbidding. However, matching protocol and group size together have significant effects on contest behavior. Partner matching reduces both the absolute level of bids and overbidding in group size 2. But the effect vanishes with a bigger group size. Furthermore, in both matching protocols a reduction in group size does not lead to an increase in bidding as predicted by theory. This implies that overbidding rate is lower in smaller groups. Finally, dispersion in bids is lower in group size 2 but matching protocol does not have an effect on bid-dispersion.

Each of the results has implications for our understanding of behavior in contests as well as of methodological issues in designing contest experiments. We find possible tacit collusion for group size 2 but none for group size 3. It is well known from the experimental literature on cartels (e.g., Fonseca and Normann, 2012) that an increase in the group size only reduces the likelihood of a tacit collusion. It is hence very likely to perceive no tacit collusion or difference in bids for group size more than 3 as well. As argued in the introduction, in case the bids are not affected by the matching protocol, a partner matching may be preferred. The first result, thus, provides a clear preference for a partner matching for group size 3 or above from a logistics point of view.

The second result does not support the equilibrium prediction that bids will increase in smaller groups. In this respect, it reconfirms and extends Lim et al. (2014) who find, under stranger matching, that group size does not have an effect on the level of bids. We, however, do find that wasteful overbidding is lower in smaller groups. In this respect, our results is in line with that of the market experiment of Fonseca and Norman (2012) who find higher level of tacit collusion for smaller market size. 
Successful collusion among players requires coordination of actions. The literature has identified a few ways to promote collusion, specifically to reduce overbidding, in contests. Cason et al. (2012) find that pre-play communication allows players to collude and leads to lower bids. Giving subjects the option to offer side-payments (Kimbrough and Sheremeta, 2013) or to use a randomization device such as the flip of a coin (Kimbrough et al., 2014) allows subjects to even avoid the contest altogether. In the absence of such communication or other explicit enforcement mechanisms, players must find other ways to learn about the behavior of others in their group. Our finding that conflict does not increase in smaller groups suggests an explanation.

In our experiment, players receive only aggregate information about group behavior. In group size 3, a player can thus only observe the combined bid of the others in his group. Hence, there is no clear benchmark action on which to coordinate. This also makes it difficult for players to send signals to the others in the group or to build reputations for cooperativeness. In group size 2, such aggregate information is equivalent to the bid of the other player. As a result, players in two player groups can observe each other's actions perfectly and signal a willingness to collude. This is particularly so under partner matching where players can track each other's behavior over time and build reputations. Croson and Marks (1998) find that the provision of identifiable individual information in an experimental threshold public goods game with partner matching increases average contributions to the public good. Nikiforakis (2010) delineates the types of information that helps cooperation. We extend this literature by establishing that the ability to identify individual behavior (small group size) and repeated play (partner matching) have strong interaction effects that allow players to build reputations and collude effectively even in contests.

There are several dimensions in which our research can be employed and extended. The very first and obvious extension would be to explicitly manipulate information feedback and investigate the effects of group size and matching protocol. It will be interesting to allow communication and observe the effects of group size in such setting. A detailed experiment to further explore the issue of bid-dispersion is needed and our procedure can be employed there. It will also be very interesting to test the robustness of our results in a field setting. 


\section{References}

Anderson, L.R., and Stafford, S.L. (2003). An Experimental Analysis of Rent Seeking Under Varying Competitive Conditions. Public Choice, 115(1-2), 199-216.

Andreoni, J., and Croson, R. (2008). Partners Versus Strangers: Random Matching in Public Good Experiments. In C.R., Plott, and V.L. Smith, (Eds.) Handbook of Experimental Economics Results Volume 1, North Holland, Amsterdam, 776-783.

Andreoni, J., \& Miller, J. H. (1993). Rational Cooperation in the Finitely Repeated Prisoner's Dilemma: Experimental Evidence. Economic Journal, 103(418), 570-85.

Binswanger, H.P. (1981). Attitudes Toward Risk: Theoretical Implications of an Experiment in Rural India. Economic Journal, 91(364), 867-890.

Botelho, A., Harrison, G.W., Pinto, L.M.C., and Rustrom, E.E. (2009). Testing Static Game Theory with Dynamic Experiments: A Case Study of Public Goods. Games and Economic Behavior, 67(1), 253-265.e3.

Cason, T.N., Sheremeta, R.M., and Zhang, J. (2012). Communication and Efficiency in Competitive Coordination Games. Games and Economic Behavior, 76(1), 26-43.

Chowdhury, S.M., and Crede, C. (2015). Post-Cartel Tacit Collusion: Determinants, Consequences, and Prevention, UEA CCP working paper No. 15-01.

Chowdhury, S.M., Kovenock, D., and Sheremeta, R.M. (2013). An Experimental Investigation of Colonel Blotto Games. Economic Theory, 52(3), 833-861.

Chowdhury, S. M., Sheremeta, R. M., \& Turocy, T. L. (2014). Overbidding and Overspreading in Rent-seeking Experiments: Cost Structure and Prize Allocation rules. Games and Economic Behavior, 87, 224-238.

Croson, R. (1996). Partners and Strangers Revisited. Economics Letters, 53(1), 25-32.

Croson, R., and Marks, M. (1998). Identifiability of Individual Contributions in a Threshold Public Goods Experiment. Journal of Mathematical Psychology, 42(2-3), 167-190.

Dechenaux, E., Kovenock, D., and Sheremeta, R.M. (2014). A Survey of Experimental Research on Contests, All-pay Auctions and Tournaments. Experimental Economics, Forthcoming.

Dolbear, F., Lave, L., Bowman, G., Lieberman, A., Prescott, E. C., Rueter, F., and Sherman, R. (1968). Collusion in Oligopoly: An Experiment on the Effect of Numbers and Information. Quarterly Journal of Economics, 88(2), 240-259.

Dufwenberg, M., and Gneezy, U. (2000). Price Competition and Market Concentration: An Experimental Study. International Journal of Industrial Organization, 18(1), 7-22.

Durham, Y., Hirshleifer, J., and Smith, V.L. (1998). Do the Rich Get Richer and the Poor Poorer? Experimental Tests of a Model of Power. American Economic Review, 88(4), 970-83.

Eckel, C.C., and Grossman, P.J. (2008). Forecasting Risk Attitudes: An Experimental Study Using Actual and Forecast Gamble Choices. Journal of Economic Behavior \& Organization, 68(1), $1-17$.

Fehr, E., and Gächter, S. (2000). Cooperation and Punishment in Public Goods Experiments. American Economic Review, 90(4), 980-994. 
Fischbacher, U. (2007). z-Tree: Zurich Toolbox for Ready-made Economic Experiments. Experimental Economics, 10(2), 171-178.

Fonseca, M. A., and Normann, H.T. (2012). Explicit vs. Tacit Collusion - The Impact of Communication in Oligopoly Experiments. European Economic Review, 56(8), 1759-1772.

Gradstein, M. (1995). Intensity of Competition, Entry and Entry Deterrence in Rent Seeking Contests. Economics and Politics, 7(1), 79-91.

Greiner, B. (2004). The Online Recruitment System ORSEE - A Guide for the Organization of Experiments in Economics, In K. Kremer, and V. Macho (eds) Forschung und wissenschaftliches Rechnen, Goettingen. 79-93.

Huck, S., Normann, H.T., and Oechssler, J. (2004). Two are Few and Four are Many: Number Effects in Experimental Oligopolies. Journal of Economic Behavior and Organization, 53(4), 435-446.

Kimbrough, E.O., and Sheremeta, R.M. (2013). Side Payments and the Cost of Conflict. International Journal of Industrial Organization, 31(3), 278-286.

Kimbrough, E.O., Sheremeta, R.M., and Shields, T.M. (2014). When Parity Promotes Peace: Resolving Conflict Between Asymmetric Agents. Journal of Economic Behavior and Organization, 99(1), 96-108.

Lacomba, J.A., Lagos, F.M., Reuben, E., and van Winden, F. (2011). On the Escalation and Deescalation of Conflict. Working Paper.

Lim, W., Matros, A., and Turocy, T.L. (2014). Bounded Rationality and Group Size in Tullock Contests: Experimental Evidence. Journal of Economic Behavior and Organization, 99, 155167.

Lugovskyy, V., Puzzello, D., and Tucker, S. (2010). An Experimental Investigation of Overdissipation in the All Pay Auction. European Economic Review, 54(8), 974-997.

Morgan, J., Orzen, H., and Sefton, M. (2012). Endogenous Entry in Contests. Economic Theory, 51(2), 435-463.

Nikiforakis, N. (2010). Feedback, Punishment and Cooperation in Public Goods Experiments. Games and Economic Behavior, 68(2), 689-702.

Price, C. R., \& Sheremeta, R. M. (2012). Endowment origin, demographic effects and individual preferences in contests. Journal of Economics and Management Strategy, Forthcoming.

Selten, R. (1973). A Simple Model of Imperfect Competition, Where Four are Few and Six are Many. International Journal of Game Theory, 2(1), 141-201.

Sheremeta, R.M. (2011). Contest Design: An Experimental Investigation. Economic Inquiry, 49(2), 573-590.

Sheremeta, R.M. (2013). Overbidding and Heterogeneous Behavior in Contest Experiments. Journal of Economic Surveys, 27(3), 491-514.

Tullock, G. (1980). Efficient Rent Seeking. In J.M. Buchanan, R.D. Tollison, and G. Tullock, (Eds.), Toward a Theory of the Rent-seeking Society. Texas A\&M University Press, College Station, TX, 97-112.

Vandegrift, D., Yavas, A., and Brown, P. (2007). Incentive Effects and Overcrowding in Tournaments: An Experimental Analysis. Experimental Economics, 10(4), 345-368. 


\section{Appendix A: Overbidding rate regressions}

Table A1. Overbidding rates: random effects panel regressions

\begin{tabular}{|c|c|c|c|c|}
\hline \multirow{2}{*}{ Dep Var: $\left(b_{i}-b^{*}\right) / b^{*}$} & \multicolumn{2}{|c|}{ Group size } & \multicolumn{2}{|c|}{ Matching protocol } \\
\hline & $\mathrm{N}=3$ & $\mathrm{~N}=2$ & Partner & Stranger \\
\hline $\begin{array}{l}\text { Stranger matching } \\
\text { Indicator }\end{array}$ & $\begin{array}{c}0.023 \\
(0.049)\end{array}$ & $\begin{array}{c}0.017^{* * *} \\
(0.006)\end{array}$ & & \\
\hline $\begin{array}{l}\text { Group size } 2 \\
\text { Indicator }\end{array}$ & & & $\begin{array}{l}-0.173^{*} \\
(0.097)\end{array}$ & $\begin{array}{r}-0.182^{* * *} \\
(0.050)\end{array}$ \\
\hline Lag of own bid & $\begin{array}{l}0.013^{* * *} \\
(0.001)\end{array}$ & $\begin{array}{l}0.013^{* * *} \\
(0.001)\end{array}$ & $\begin{array}{l}0.015^{* * *} \\
(0.001)\end{array}$ & $\begin{array}{l}0.012^{* * *} \\
(0.001)\end{array}$ \\
\hline Previous period win indicator & $\begin{array}{c}0.019 \\
(0.021)\end{array}$ & $\begin{array}{c}-0.069^{* * *} \\
(0.012)\end{array}$ & $\begin{array}{l}-0.069^{*} \\
(0.0355)\end{array}$ & $\begin{array}{c}-0.003 \\
(0.0317)\end{array}$ \\
\hline Lag of others' bid & $\begin{array}{c}0.0001 \\
(0.0006)\end{array}$ & $\begin{array}{l}0.004^{* * *} \\
(0.001)\end{array}$ & $\begin{array}{l}0.0003 \\
(0.001)\end{array}$ & $\begin{array}{l}0.0006^{* *} \\
(0.0003)\end{array}$ \\
\hline Period & $\begin{array}{c}-0.007^{* * *} \\
(0.003)\end{array}$ & $\begin{array}{c}0.001^{*} \\
(0.0006)\end{array}$ & $\begin{array}{l}-0.002 \\
(0.003)\end{array}$ & $\begin{array}{l}-0.005 \\
(0.003)\end{array}$ \\
\hline Risky behavior indicator & $\begin{array}{l}0.144^{*} \\
(0.081)\end{array}$ & $\begin{array}{c}-0.021 \\
(0.0686)\end{array}$ & $\begin{array}{l}-0.004 \\
(0.048)\end{array}$ & $\begin{array}{l}0.197^{* *} \\
(0.095)\end{array}$ \\
\hline Female indicator & $\begin{array}{l}0.047^{*} \\
(0.025)\end{array}$ & $\begin{array}{l}0.024^{* *} \\
(0.012)\end{array}$ & $\begin{array}{l}0.060^{* * *} \\
(0.013)\end{array}$ & $\begin{array}{c}0.055 \\
(0.038)\end{array}$ \\
\hline Age & $\begin{array}{l}-0.008 \\
(0.009)\end{array}$ & $\begin{array}{l}-0.001 \\
(0.007)\end{array}$ & $\begin{array}{l}-0.001 \\
(0.006)\end{array}$ & $\begin{array}{l}-0.015 \\
(0.015)\end{array}$ \\
\hline Constant & $\begin{array}{l}-0.114 \\
(0.288)\end{array}$ & $\begin{array}{c}-0.661^{* * *} \\
(0.151)\end{array}$ & $\begin{array}{l}-0.365 \\
(0.229)\end{array}$ & $\begin{array}{c}0.003 \\
(0.414)\end{array}$ \\
\hline$R^{2}$ & 0.29 & 0.43 & 0.36 & 0.29 \\
\hline Observations & 2592 & 1728 & 2160 & 2160 \\
\hline
\end{tabular}

Figures in parentheses are robust standard errors clustered on sessions. ${ }^{*} p<0.10,{ }^{* *} p<0.05,{ }^{* * *} p<0.01$. 


\section{Appendix B: Instructions}

Below we provide the instructions used in this experiment. We provide the instructions for partner treatment; and use appropriate phrases in bracket and shade the phrases that are changed in the stranger treatment.

\section{GENERAL INSTRUCTIONS}

This is an experiment in the economics of decision making. This experiment consists of two unrelated parts. Instructions for the first part are given next and the instructions for the second part will be provided after the first part of the experiment is finished.

The instructions are simple. If you follow them closely and make appropriate decisions, you can earn an appreciable amount of money.

It is very important that you remain silent and do not look at other people's work. If you have any questions, or need assistance of any kind, please raise your hand and an experimenter will come to you. If you talk, laugh, exclaim out loud, etc., you will be asked to leave and you will not be paid. We expect and appreciate your cooperation.

Experimental Currency is used in the experiment and your decisions and earnings will be recorded in tokens. At the end of today's experiment, you will be paid in private and in cash. Tokens earned from both parts of the experiment will be converted to Pound Sterling at a rate of:

$\underline{\mathbf{1}}$ token to $\underline{\mathbf{3}}$ Pence (£0.03). 


\section{INSTRUCTIONS - PART 1}

In this task, you will be asked to choose from six different gambles (as shown below). Each circle represents a different gamble from which you must choose the one that you prefer. Each circle is divided in half, with the number of tokens that the gamble will give you in each circle.
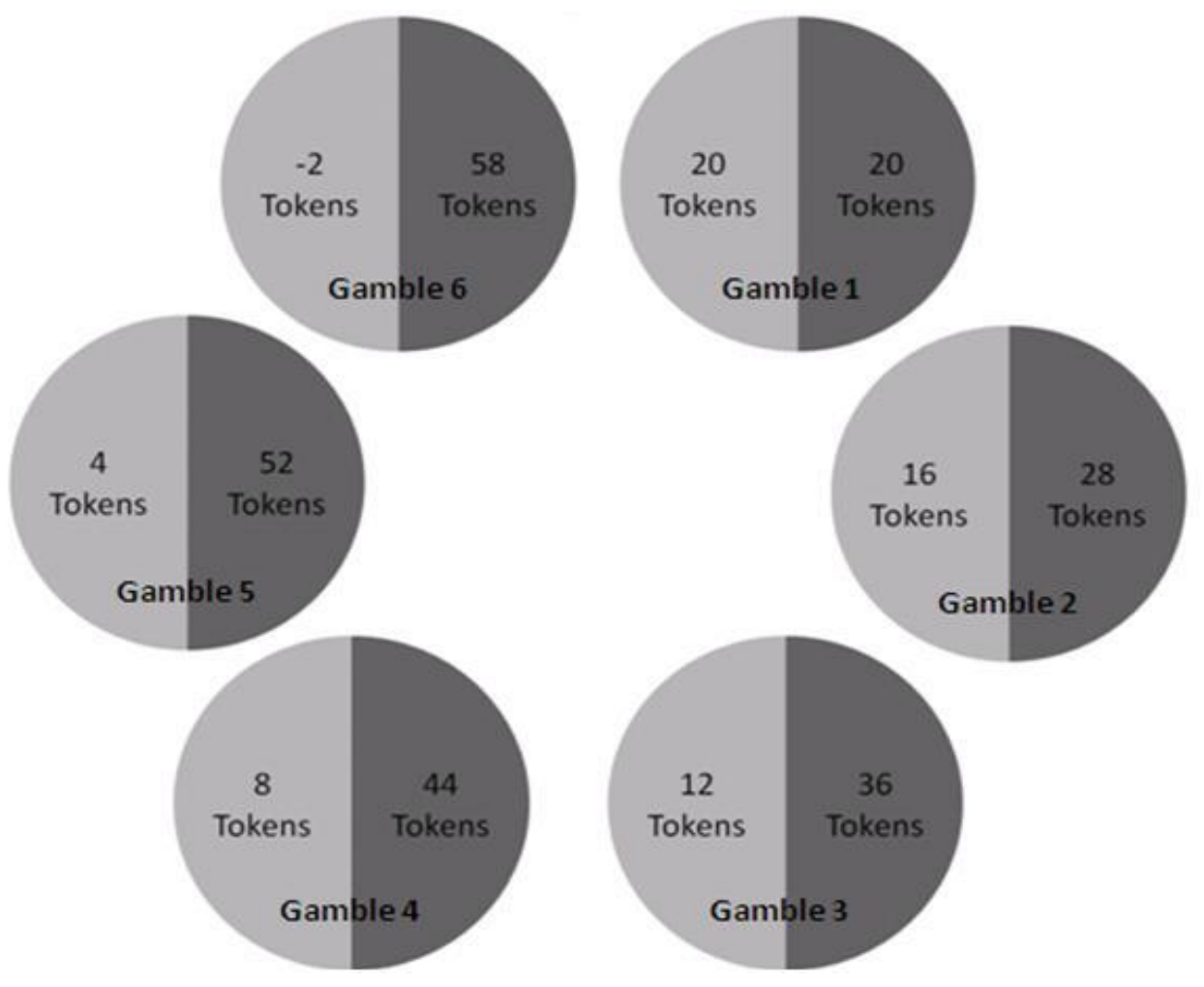

Your payment for this task will be determined at the end of today's experiment. A volunteer will come to the front of the room and toss a coin. If the outcome is heads, you will receive the number of tokens in the light grey area of the circle you have chosen. Alternatively, if the outcome is tails, you will receive the number of tokens shown in the dark grey area of the circle you have chosen. Note that no matter which gamble you pick, each outcome has a 50\% chance of occurring.

Please select the gamble of your choice by clicking one of the "Check here" buttons that will appear on each circle in the picture Once you have made your choice, please click the "Confirm" button at the bottom of the screen.

For your record, also tick the gamble you have chosen in the above picture.

Once everyone has made their decision, this task will end and we will move on to Part 2 of the experiment. Your payment for this task will be decided at the end of today's experiment. 


\section{INSTRUCTIONS - PART 2 [For $N=3$ ]}

\section{YOUR DECISION}

This part of the experiment consists of $\mathbf{2 5}$ decision-making periods. At the beginning, you will be randomly and anonymously placed into a group of $\mathbf{3}$ participants. The composition of your group will remain the same for all 25 periods [will be changed randomly every period]. You will not know who your group members are at any time.

Each period you will receive an initial endowment of $\mathbf{1 8 0}$ tokens. Each period, you may bid for a reward of 180 tokens. You may bid any number between $\mathbf{0}$ and 180 (including 0.1 decimal points). An example of your decision screen is shown below.

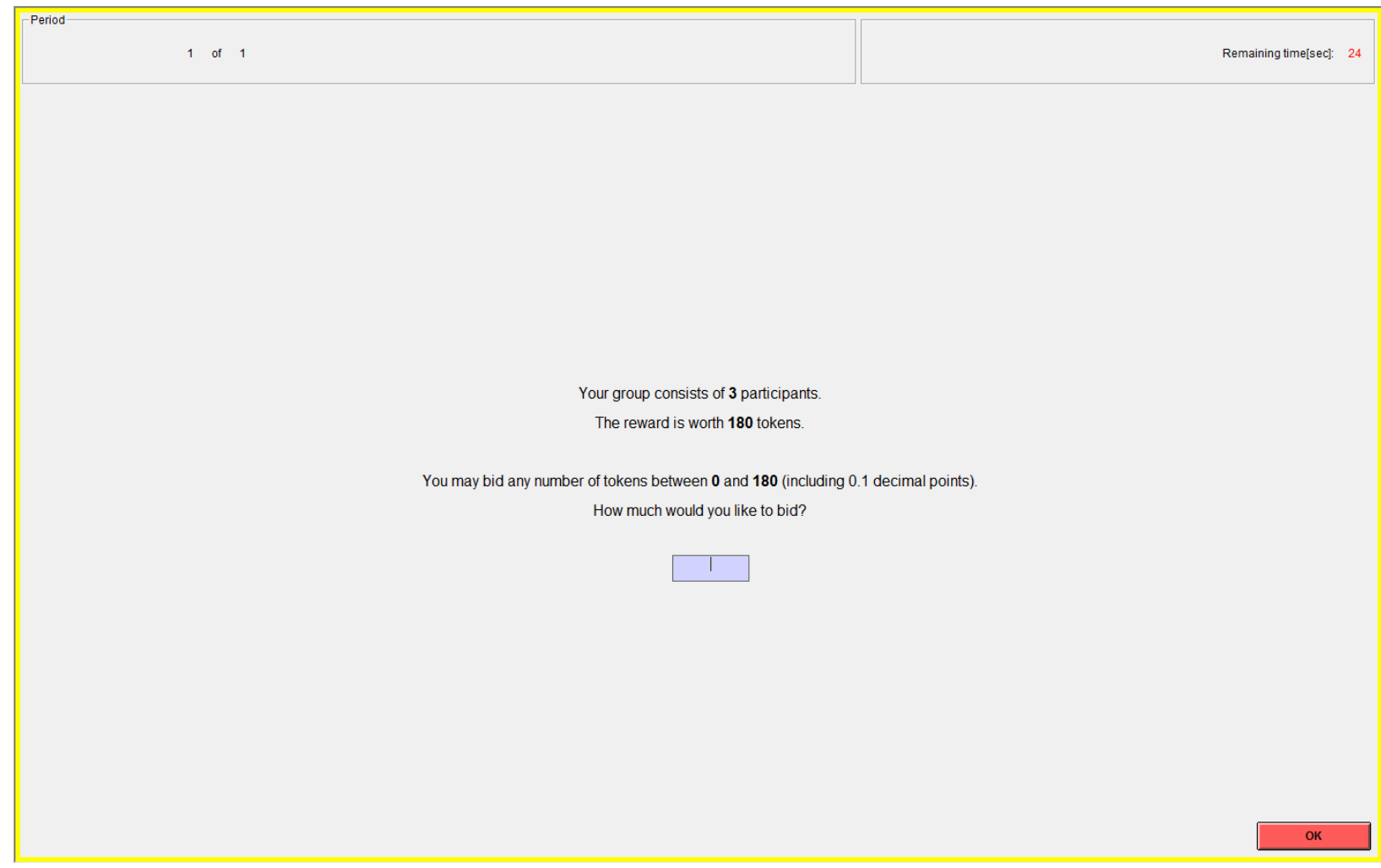

\section{YOUR EARNINGS}

For each bid there is an associated cost equal to the bid itself. The cost of your bid is:

Cost of your bid $=$ Your bid 
The more you bid, the more likely you are to receive the reward. The more the other participants in your group bid, the less likely you are to receive the reward. Specifically, your chance of receiving the reward is given by your bid divided by the sum of all 3 bids in your group:

$$
\text { Chance of receiving the reward }=\frac{\text { Your bid }}{\text { Sum of all } 3 \text { bids in your group }}
$$

You can consider the amounts of the bids to be equivalent to numbers of lottery tickets. The computer will draw one ticket from those entered by you and the other participants, and assign the reward to one of the participants through a random draw. If you receive the reward, your earnings for the period are equal to your endowment of 180 tokens plus the reward of 180 tokens minus the cost of your bid. If you do not receive the reward, your earnings for the period are equal to your endowment of 180 tokens minus the cost of your bid. In other words, your earnings are:

If you receive the reward: Earnings $=$ Endowment + Reward - Cost of your bid $=180+180-$ your bid If you do not receive the reward: Earnings $=$ Endowment - Cost of your bid $=180-$ your bid

\section{$\underline{\text { An Example (for illustrative purposes only) }}$}

Let's say participant 1 bids 30 tokens, participant 2 bids 45 tokens and participant 3 bids 0 tokens. Therefore, the computer assigns 30 lottery tickets to participant 1, 45 lottery tickets to participant 2 and 0 lottery tickets to participant 3 . Then the computer randomly draws one lottery ticket out of 75 $(30+45+0)$. As you can see, participant 2 has the highest chance of receiving the reward: $\mathbf{0 . 6 0}=$ 45/75. Participant 1 has $\mathbf{0 . 4 0}=\mathbf{3 0 / 7 5}$ chance and participant 3 has $\mathbf{0}=\mathbf{0} / \mathbf{7 5}$ chance of receiving the reward.

Assume that the computer assigns the reward to participant 1 , then the earnings of participant 1 for the period are $330=180+180-30$, since the reward is 180 tokens and the cost of the bid is 30 . Similarly, the earnings of participant 2 are $135=180-45$ and the earnings of participant 3 are $180=180-0$.

At the end of each period, your bid, the sum of all 3 bids in your group, your reward, and your earnings for the period are reported on the outcome screen as shown below. Once the outcome screen is 
displayed you should record your results for the period on your Personal Record Sheet (page 4) under the appropriate heading.

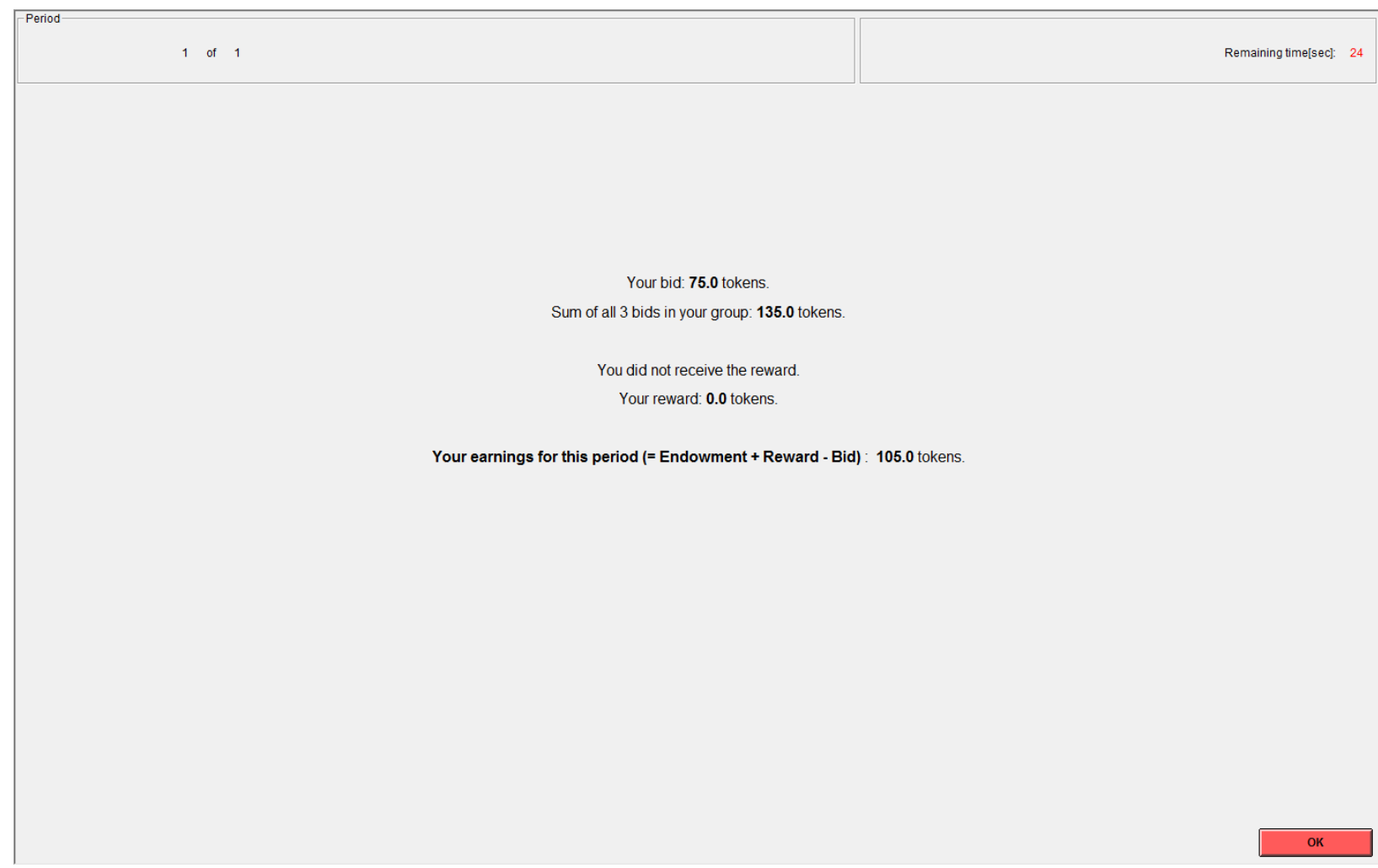

\section{IMPORTANT NOTES}

At the beginning of this part of the experiment [At the beginning of each period of this part of the experiment] you will be randomly grouped with another two participants to form a 3-person group. You will not be told which of the participants in this room are assigned to which group.

At the end of the experiment the computer will randomly choose 5 of the 25 periods for actual payment for this part of experiment. You will be paid the average of your earnings in these 5 periods. These earnings in tokens will be converted to cash at the exchange rate of $\underline{1}$ token to $\underline{\mathbf{3}}$ Pence (£0.03) and will be paid at the end of the experiment.

\section{Are there any questions?}




\section{Personal Record Sheet}

( 5 periods from here will be randomly chosen for final payments)

\begin{tabular}{|c||l|l|l|l|}
\hline Period & Your bid & $\begin{array}{c}\text { Sum of all 3 } \\
\text { bids in your } \\
\text { group }\end{array}$ & Your reward & $\begin{array}{c}\text { Your } \\
\text { earnings for } \\
\text { this period }\end{array}$ \\
\hline 1 & & & & \\
\hline 2 & & & & \\
\hline 3 & & & & \\
\hline 4 & & & & \\
\hline 5 & & & & \\
\hline 6 & & & & \\
\hline 7 & & & & \\
\hline 8 & & & & \\
\hline 9 & & & & \\
\hline 10 & & & & \\
\hline 11 & & & & \\
\hline 12 & & & & \\
\hline 13 & & & & \\
\hline 14 & & & & \\
\hline 15 & & & & \\
\hline 16 & & & & \\
\hline 17 & & & & \\
\hline 18 & & & & \\
\hline 19 & & & & \\
\hline 20 & & & & \\
\hline 21 & & & & \\
\hline 22 & & & & \\
\hline 23 & & & & \\
\hline 24 & & & & \\
\hline 25 & & & & \\
\hline
\end{tabular}




\section{Total Earnings}

\begin{tabular}{|l|l|}
\hline Period Chosen & Earnings for this period \\
\hline & \\
\hline & \\
\hline & \\
\hline & \\
\hline Total & \\
\hline
\end{tabular}

Total earnings from table above:

Average of above earnings: $(1) \div 5$

Earnings from Part 1:

Total earnings $\quad(2)+(3)$

Multiply by exchange rate:

(4) $\times \underline{0.03}$

Total payment for the experiment:

$\underline{\mathfrak{f}}$ 


\section{QUIZ}

1. Does group composition change across periods in the experiment?

Ans. Yes No

2. What is the value of 1 token in Pence?

Ans. 3 Pence 6 Pence 9 Pence

\section{Questions 3 to 7 apply to the following information.}

In a given period, suppose the bids by participants in your group are as follows.

Bid of participant 1: 55 tokens

Bid of participant 2: 70 tokens

Bid of participant 3: 10 tokens

3. What is the chance that participant 1 will receive the reward?

Ans.

out of

4. What is the chance that participant 2 will receive the reward?

Ans.

out of

5. What is the chance that participant 3 will receive the reward?

Ans.

out of

6. If you are Participant 1 and you did not receive the reward what are your earnings this period?

Ans. tokens

7. If you are Participant 2 and you received the reward what are your earnings this period?

Ans. tokens 


\section{EXPLANATIONS FOR QUIZ ANSWERS}

1. Does group composition change across periods in the experiment?

Ans. $\quad \underline{\text { No }}[\underline{Y e s}]$

2. What is the value of 1 token in Pence?

Ans. $\quad \underline{3 \text { Pence }}$

3. What is the chance that participant 1 will receive the reward?

Ans. $\quad \underline{55}$ out of $\underline{135}$.

4. What is the chance that participant 2 will receive the reward?

Ans. $\quad \underline{70}$ out of $\underline{135}$.

5. What is the chance that participant 3 will receive the reward?

Ans. $\quad \underline{10}$ out of $\underline{135}$.

6. If you are Participant 1 and you did not receive the reward what are your earnings this period? Ans. 125 tokens $\quad(=$ Endowment - bid $=180-55)$

7. If you are Participant 2 and you received the reward what are your earnings this period? Ans. 290 tokens $\quad(=$ Endowment + Reward - Bid $=180+180-70)$ 